\title{
IRRIGATION IN THE SIBENIK-KNIN COUNTY
}

\author{
RADIC LAKOS, T[anja] \& RADACIC, M[arko]
}

\begin{abstract}
The goal of this paper is to present the irrigation issues on the example of the Sibenik-Knin County. New agricultural production technologies have been developed, among which we should emphasize the technologies such as GIS and GPS, as well as the automatic irrigation systems. Due to the need to ensure a reduced impact on the consumption of natural resources and sustainable development in general, as well as the need to irrigate the observed area in the future, it is proposed to implement the new technologies.

Keywords: irrigation, GIS, GPS, agriculture
\end{abstract}

\section{INTRODUCTION}

The integration and implementation of contemporary information and communications technologies in agriculture is most certainly a step toward success. Since ancient times, people have strived to simplify, facilitate and improve the work methods, tools and aids applied in agriculture, which is exactly what the current achievements in the field of science and technology make possible. The minimization and optimization of processes and methods of production lead to a more efficient use of resources; from the use of fertilizers, pesticides, herbicides and water, to a better and more optimal use of cultivation areas. All this contributes to the increase in the quantity and quality of the products obtained through cultivation, thus also to achieving higher profits.

\section{RESEARCH METHODOLOGY}

For the purposes of this paper, the descriptive method of presenting new technologies applied in agriculture was used. The paper provides a brief presentation of the condition of agricultural production in the Sibenik-Knin County (Croatia). The main advantage of using the descriptive method is the possibility of presenting the condition in one place. It is, however, the purpose of this paper to emphasize the need to introduce the best available techniques in future agricultural production in the observed area as the only solution to achieving sustainable agriculture.

\section{IRRIGATION ISSUES: THE SIBENIK-KNIN COUNTY EXAMPLE}

The Sibenik-Knin County is situated between the Northern and Central Dalmatia and Lika, and is characterized by diversities evident primarily in the natural features of the region that is divided into the continental area and the hinterland, and the coastal area and the islands. The County has a total area of 5659.79 square kilometers. The land area accounts for $52.8 \%$ and the water area for $47.2 \%$ of the total area. The County's population density is only $60 \%$ of Croatia's average with a trend of emigration from the islands and moving to the coast. The County thus represents a part of Croatia strongly affected by exodus, emigration and depopulation processes. It is well known that the stumbling industry has been losing importance for years and that the County has chosen tourism, accommodation and food services as its strategic development focus in the coastal area and agriculture in the continental area, i.e. a blue/green combination.

Most of the land in the County is only marginally suitable or completely unsuitable for agriculture. Only a small part of the land may be classified as moderately suitable for agriculture, although with significant limitations. Within this part, there are small areas which are highly suitable for agriculture. The islands and the coastal area are characterized by the lack of fertile land. Of almost 180,000 ha of agricultural land in the County, only 40,000 ha are cultivable. The agro-ecological conditions for the development of agricultural crops are excellent, but the problems arise due to a small and insufficient quantity of water. More precisely, during the entire vegetation period the Sibenik-Knin County records insufficient precipitation for successful cultivation of agricultural crops.

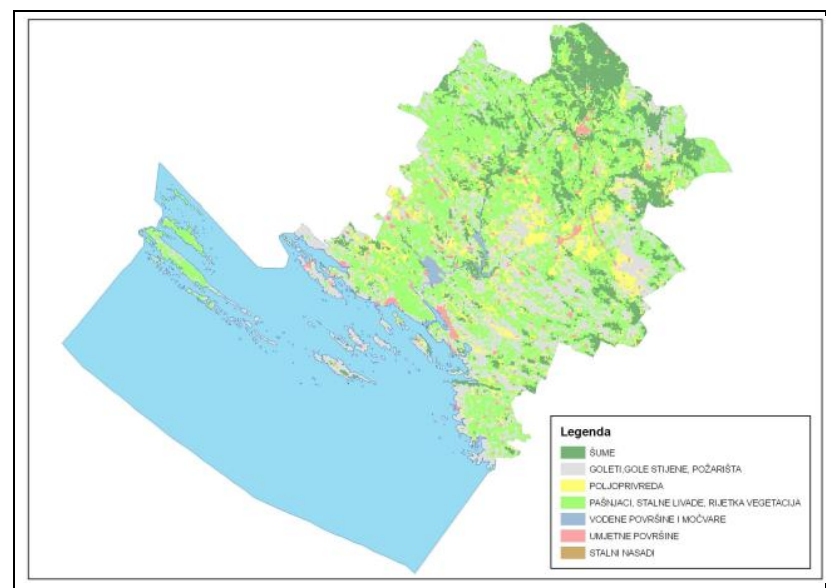

Fig. 1.Vegetation cover in the Sibenik-Knin County (Legend: up to down: forests; barren land, barren cliffs, burnt areas; agriculture; pastures, permanent meadows, scarce vegetation; water areas and swamps; artificial areas; permanent plantations) [1]

\subsection{Existing Condition of Agricultural Land}

The total agricultural land area of the County is 179,570 ha. Most agricultural land is privately owned (especially referring to orchards and olive plantations that are 99 to $100 \%$ privately owned). 
By ensuring the supply of irrigation water, the land under pastures would be reduced; the land under vegetable, fruit and flower crops (which are more profitable) would be increased; the costs incurred due to severe droughts (appearing in general every three years) would be avoided; and the need for new workforce would be increased as well.

By analyzing the ecological conditions in the Sibenik-Knin County, it can be concluded that the conditions for cultivation of a large number of fruit species (olives, almonds, figs, sweet cherries, sour cherries, plums, apples, walnuts, peaches, apricots, quinces, mountain ash berries and gall nuts), vine, as well as vegetable and flower crops exist on the territory of the County. The mentioned fruit species are grown in extensive or semi-intensive conditions, most frequently in consolidation with vine.

\begin{tabular}{|c|c|c|c|c|c|c|c|}
\hline 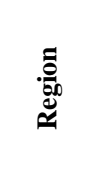 & 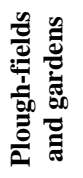 & $\begin{array}{l}\frac{n}{0} \\
\frac{0}{0} \\
0 \\
0\end{array}$ & 㟢 & 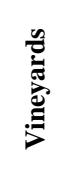 & 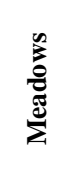 & 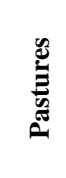 & 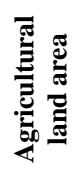 \\
\hline Sibenik & 9.34 & 2.9 & 2.23 & 3.21 & 1.46 & 80.9 & 100 \\
\hline Drnis & 41.9 & 0.22 & 0.02 & 4.75 & 1.48 & 52.2 & 100 \\
\hline Knin & 5.40 & 0.08 & 0.00 & 0.42 & 8.91 & 85.2 & 100 \\
\hline County & 12.9 & 1.37 & 1.00 & 2.37 & 4.37 & 77.9 & 100 \\
\hline
\end{tabular}

Tab. 1. Land-use categories in the Sibenik-Knin County (in \%) [1]

Although the annual precipitation quantity varies from year to year, it is still insufficient to ensure high volume production and quality of fruit species. We should understand the higher resistance of particular plant species to drought as a mechanism for surviving in bad ecological conditions of the habitat, and not as a possibility of ensuring good vegetative development and quality of the crop yield. Safe and quality plant production can be ensured only by implementing irrigation technology.

\subsection{Irrigation Possibilities}

The Sibenik-Knin County is a typical karst area characterized, among other, also by very limited agricultural land resources. In this area, the soil is one of the more important natural values and represents a significant natural resource. The agrarian structure of the County is predominated by family agricultural estates (especially referring to orchards and olive plantations that are 99 to $100 \%$ privately owned). The problem is that these estates are very small. They range in size from 0.36 to 3.24 ha of used land and the used parcels are even smaller (the average size of the parcel is $0.15 \mathrm{ha}$ ), which indicates to the fact that almost none of these estates are market-oriented. It is, therefore, necessary to start increasing the size of family estates and production parcels. The second important factor in terms of the economic justifiability of investing into irrigation systems is the availability of irrigation water. The sources of irrigation water are diverse. Most frequently used, however, is the water from free lake and spring water flows, underground water or waters accumulated in natural or artificial accumulation lakes.

The water used for irrigation purposes must meet certain criteria in order to ensure that plants, agricultural land or irrigation devices are not harmed due to the use of the same. Saltwater intrusion affecting agricultural land is recognized today as one of the greatest ecological problems. Saltwater intrusion may occur if water of undefined quality is used for irrigation. The possibility of using a certain type of water for irrigation purposes is therefore determined on the basis of the analysis of water quality taking into consideration the relevant plant, type of soil, climate, as well as the agro-technical, sanitary and ecological conditions. In this process, it is extremely important to ensure that the quantity of water envisaged for irrigation purposes does not disrupt the water supply or have impact on the water used for the purpose of producing electrical energy (hydropower plants).

\subsection{Existing Condition of Irrigation}

Irrigation is one of the oldest melioration measures in general. In Croatia, irrigation has been around for a long time. It has, however, never been systematically developed, so that there is no tradition of irrigation in our country. Former individual examples have proved absolutely justified as greater crop yields and agricultural products of higher quality have been obtained under irrigated conditions. According to the 2003 Agricultural Census [2], there are only 9,264 ha of irrigated land in Croatia, i.e. only $0.46 \%$ of total cultivable land. Only 61.11 ha, i.e. $0.56 \%$ of total used land in the SibenikKnin County, are irrigated.

Most of the irrigation activities take place in the Knin area (25.27 ha), followed by the Drnis, Skradin and Sibenik areas. In addition to the mentioned areas, there are also certain micro-locations in the field that were not included in the agricultural census or in the case of which irrigation started after 2003. In spite of that, irrigation has not been systematically developed in the county.

Extensive plans for irrigating the County had existed until two years ago. In 2006, extensive documentation and various detailed plans, including the Irrigation Plan, were drawn up; concept designs were also prepared and research activities carried out.

There was also much talk about the construction of the Cikola accumulation lake. Since 2006, when only 61.11 ha, i.e. $0.56 \%$ of total used land, were irrigated, not much has changed until today partly due to the unexpected discovery of salty water on the territory of Petrovo polje and partly due to the economic crisis that entailed problems concerning further financing of projects.

It is an unquestionable fact that there is potential for greater agricultural development in this region. In the future, it will be necessary to increase the land under agricultural crops using the best available techniques.

\section{CHOICE OF IRRIGATION METHODS, MODES AND SYSTEMS}

Since irrigation was first introduced in agriculture until today, four irrigation methods, several irrigation 
modes and numerous irrigation systems have been used. The first method was the surface irrigation method. The main feature of this method lies in that the water covers the soil in a thin layer or runs across the surface while being absorbed into the rhizosphere. Surface flow irrigation modes and systems are still used around the world, especially the furrow irrigation system. The next method is the underground irrigation method. The water is brought onto the production parcel through open channels or underground pipes. Under the influence of capillary forces, the water is infiltrated both horizontally and vertically into the rhizosphere. It is, however, not recommended to use either of the two mentioned methods in the Sibenik-Knin County.

The sprinkler irrigation method was first used at the beginning of the $20^{\text {th }}$ century when new techniques and more efficient machines were developed. The application of advanced equipment made it possible to bring pressurized water onto production areas. Several irrigation modes and systems have been developed within the scope of the sprinkler irrigation method as well. There are today various classic sprinkler irrigation systems, automated machine systems and several hydromatic systems that sprinkle and dosage water in accordance with the needs of the soil, the cultivated crop and production goals. The localized irrigation method is the most recently developed irrigation method (people started using it in the middle of the past century). There are today several drip irrigation systems as well as various mini sprinkler irrigation systems as well.

\section{NEW TECHNOLOGIES AND MODES OF CULTIVATION}

The main phases of agricultural industry include: crop cultivation, water management, fertilizer application, pest protection, harvest, transport of food/food products, packaging, preservation, storing and processing of food, food quality management, etc.

The agricultural production technology today also includes the following techniques [3]:

- assessment of cultivable land using GIS technology,

- GPS systems,

- automation of agricultural equipment using microchips,

- guiding systems,

- automated irrigation and fertilizer application systems,

- sprinkler and drip systems,

- devices for monitoring various parameters (humidity control, soil temperature, $\mathrm{pH}$ measuring and measuring of basic nutrients in the water or soil),

- computer programs used to make analyses and forecasts related to the use and consumption of resources,

- biotechnology,

- crop rotation,

soil improvement,

recycling/composting,

polyculture,

hydroponics,

aquaponics,

aeroponics,
- ecological agriculture,

- urban planning,

- permaculture, etc.

\subsection{Geographic Information System}

GIS is a system designed to capture, store, manipulate, analyze, manage and present all types of geographical data. It could be said that GIS is a combination of cartography, statistical analyses and database technologies. GIS organizes the geographical data in such a manner so as to allow the person that uses the maps to select the data relevant to a specific project or task performed. A good GIS program can process geographical data obtained from various sources and integrate them into a joint project.

Users can manipulate the map on the display in various ways: they can change direction, zoom specific areas in or out, as well as change the properties of the information contained in the map [4].

The possibility provided to agriculturists to analyze and present agricultural land and work flow using a GIS system has proved quite useful to those engaged in agricultural industry. The scope of application of GIS technology has increased from mobile GIS systems intended for field application to scientific analyses of production system databases, thus ensuring a reduction in agricultural production costs and more efficient soil and agricultural land management. The natural conditions at a specific location must not be changed, but it is possible to gain a better understanding of the same and use them through GIS applications for the purpose of crop yield forecasting, soil enhancement analyses, erosion forecasting and correction, and similar. The companies engaged in the sale of pesticides can use the databases to analyze pest migration trends as well as to ensure that pesticides are used in accordance with the same. Farmers can use GIS technology to assess the game habitat risks, make crop stress analyses, and similar.

One of the methods for collecting data for GIS systems is the so-called 'remote sensing'. There are two types of remote sensing: passive and active sensing. Passive sensors detect the natural radiation that is radiated or reflected from the observed objects or surface. Reflected solar radiation is the most frequent source of radiation measured by passive sensors, while the devices for active sensing must emit a certain dose of radiation in order to be able to scan the objects and areas using the emitted radiation which is reflected or dispersed over the target area.

Observation satellites in the Earth's orbit, such as the Landsat Program and the IKONOS Satellite, are used for passive sensing, but there are also several dozen other satellites used for similar purposes.

Active sensing is performed using a device called LIDAR (Light Detection and Ranging). This technology is based on the knowledge of the speed of light and a narrow coherent laser ray beam emitted by the device into space. The device measures the time required for the laser ray impulse to travel to the obstacle and back to the sensor. Using the distance and the angles, i.e. the space between the measured points, each of them may be presented in space with its spatial 3D coordinates. Depending on the device and its intended application, 
continuous and quick measuring of such points actually represents spatial scanning which is widely applied, in the field of agriculture as well, to detect insufficiency or surplus of nutrients, water, weed infestation, damage caused by insects, hail, wind, herbicides, and plant population monitoring. The information obtained through remote sensing can be used as the basis for making maps used by agriculturists for variable rate application of nutrients, water, herbicides, insecticides and pesticides, thus treating separate areas using specifically determined quantities required to ensure optimum cultivation and achieving savings on raw materials used in the process. With the help of these remote sensing systems, possible problems that can occur in connection with agricultural crops may be prevented even prior to being visually noticeable.

\subsection{Global Positioning System}

GPS offers the agriculturists the possibility to manage their land and crops in a more precise manner. The common terms used to denote the general use of GPS applications are: precise agriculture, location-specific agriculture, and similar. The use of GPS technology in the field of agriculture includes the guiding of equipment such as sprinklers, fertilizer applicators and plough machines in order to reduce the unnecessary overlaps and omissions [5]. GPS technology can be used for precise locating of places where soil samples are taken, for mapping of weeds, plant diseases and field insect infestations, as well as for the application of the variable crop condition and recording of crop yields.

GPS can also be used to guide agricultural equipment and machinery. Target spraying may be given as an example. Insects do not affect the fields evenly spread but in groups concentrated in particular areas. A field worker can use GPS to record the locations where the insects are concentrated, and such data can be sent to pilots driving the planes with sprayers, thus allowing selective spraying instead of treating the entire field. Methods such as these result in time, fuel and insecticide savings, as well as reduced exposure of crops to chemicals.

GPS technology can also be used to automate the entire plugging and sowing process. Detailed GPS field maps in combination with an adequate system allow the agriculturists to program a tractor to perform certain tasks automatically.

The gathering of soil samples has been greatly facilitated with the implementation of GPS systems. The locations where the samples are taken are recorded and stored. After the laboratory delivers the results of the soil analysis, the relevant data can be used together with the exact locations where the samples were taken. All the gathered data are then entered in the map for the purpose of facilitating the process of making decisions regarding the treatment of particular parts of the land applying the specific methods required.

\subsection{Automatic Irrigation System}

Since the water supplies are becoming increasingly scarce and polluted, the need for a more efficient irrigation system which would reduce the quantity of water and chemicals used for agricultural purposes has arisen. This system makes possible a $70 \%$ water use reduction compared to the old-fashioned agricultural methods without producing any negative effects on the crop yield. Future research efforts aimed at improving this method should include the development of techniques eliminating the need for soil-specific calibrations.

The drip irrigation system ensures the most rational use of water compared to other irrigation methods. This method ensures a continuous distribution of a small quantity of water in a unit of time, thus causing no plant stress or soil compression. Besides ensuring the supply of water, the system also makes it possible to bring the topdressing and protection materials to the plants. In addition, such a system presupposes a low workload, thus making it the most rational method compared to other irrigation methods in terms of power consumption as well. The basic principle of the drip irrigation method is that the water flows out of the installed plastic pipes through special droppers installed alongside the pipes, thus drip watering the soil along each planted seedling or plant of interest [6]. By applying this method, the soil water requirements are most precisely satisfied.

Electronic devices of the system for monitoring the irrigation process, climatic conditions and water are also used.

\section{CONCLUSION}

The new innovations and regulations aimed at ensuring agricultural sustainability will be of critical importance if we wish to meet the crop yield improvement requirements without compromising the environment and people's health. However, even though cultivation sustainability is more easily achievable if new technologies are applied, one should be careful and learn how to use them properly in order to realize that goal. The implementation of new technologies makes it possible to realize equal crop yields using a reduced agricultural land area and smaller quantities of resources required for cultivation, while achieving higher profits.

\section{REFERENCES}

[1] Tomić, F. \& all (2006) Šibenik-Knin County Irrigation. Detailed Plan. Zagreb-Split

[2] Croatian Bureau of Statistics (2003). Agricultural Census. Available from: http: http://www.dzs.hr/Hrv/censuses/Agriculture2003/ census_agr.htm

[3] Ess, D. \& Morgan, M. (1997). The Precision-Farming Guide for Agriculturists. Moline, IL

[4] Yeung, A. K. W. \& Pang, L. C. (2002). Concepts and Techniques of Geographic Information Systems. Upper Saddle River. New York

[5] Stombaugh, T.; Shearer, S. \& Fulton, J. (2002). GPS Simplified. University of Kentucky Ext. Rept. PA-5

[6] Burt, C. M. \& Barreras, J. (2001). Retrievable Drip Tape Irrigation Systems: An Alternative to SDI. Irrigation Journal 51(3):17-20 